\title{
Relation Between Gender Role and Interpersonal Relations of Chinese College Students
}

\author{
Zhenxin $\mathrm{Du}^{1, \dagger, \mathrm{a},{ }^{*}, \text { Jiaqi Guo }}{ }^{2, \dagger}$, Jiahua Wang ${ }^{3, \dagger}$, Leyi Xie ${ }^{4, \dagger, b, *}$ \\ ${ }^{1}$ School of Foreign Languages, Shanghai University, Shanghai, China \\ ${ }^{2}$ School of Sports, Xihua University, Chengdu, Sichuan, China \\ ${ }^{3}$ School of Education, Hebei Normal University, Shijiazhuang, Hebei, China \\ ${ }^{4}$ School of Education, Beijing Normal University Zhuhai, Zhuhai, Guangdong, China \\ These authors contributed equally \\ *Corresponding author's e-mail: adlq521223@shu.edu.cn, ${ }^{b} 1811010006 @$ mail.bnuz.edu.cn
}

\begin{abstract}
The college period is an important stage in the development of gender role, which is also a key period in interpersonal relations. At present, many college students in China are facing the pressure of interpersonal communication, and even have difficulty dealing with interpersonal relationships. Previous studies have shown that gender role is an important factor affecting the harmony of college students' interpersonal relations. Therefore, this paper aims to explore the relationship between the four gender role types and interpersonal relations, and the impact of the four gender role types on the interpersonal relations of Chinese college students. We find that college students whose gender roles are masculine and androgynous have the most harmonious interpersonal relations mode. Besides, college students who are feminine and undifferentiated are more likely to have problems in interpersonal relations. Moreover, suggestions are proposed in order to improve the interpersonal harmony of Chinese college students. Specifically, families, schools, society and media should actively guide college students to develop in the direction of masculinity and androgyny, so as to promote their physical and mental health and adapt to the society. These results offer a guideline that we need to foster more college students whose gender role types are masculine and androgynous in order to improve their interpersonal harmony.
\end{abstract}

Keywords: Gender role, Interpersonal relations, Chinese college students.

\section{INTRODUCTION}

The importance of social life cannot be overstated. which helps establish a connection with community that is essential to students' mental health and academic performance. However, if students are plainly arrogant, obsessive, shy or avoidant, socializing with people can be stressful. According to the Ref. [1], about $72 \%$ of college students are troubled in interpersonal communication to varying degrees. Some people attribute the success of socialization to the personality of extrovert or introvert. In traditional belief, extroverts are more likely to build good relationships with others while introverts are difficult to do so. Besides, many people also have the stereotypes about masculine and feminine. In specific, female is a good listener who care about others, feelings, while male is more likely to stand out of the crowd and lacks of humility.
While biological sex is a dichotomy of either male or female, the notion of gender should not be limited to the two extremes. It is important to use a sophisticated conceptualization of gender to demonstrate that gender role accounts for more of the interpersonal relationship than the conventional gender variable, which is sex [2]. Bem compiled the Bem Gender Role Questionnaire (CSRI) divided gender roles into four types: masculine, feminine, androgynous and undifferentiated [3]. Masculine individuals have stronger masculine characteristics and feminine individuals have stronger feminine characteristics. Androgynous individuals have both masculine and feminine characteristics, and they are more active, while undifferentiated individuals have weaker masculine and feminine characteristics [4].

For developing and shaping individuals' gender role, college life is a critical period. If one doesn't pay attention to it, the disregard negatively affects their future 
career and life [5]. Therefore, emphasis should be laid on how college students shape their cognition of gender role and its impact on social life.

However, scholars did not reach a common consensus on which type of gender roles is the most conducive to interpersonal communication. Liu holds that male and female androgynous individual interpersonal communication mode is the most harmonious [6]. Different statements in Ref. [7] argues that both men and women showed the most harmonious interpersonal communication pattern with masculine qualities. It is still inconclusive that which gender role type is more conducive to interpersonal communication [8]. On this basis, the purpose of this study is to explore the relationship between gender role types and interpersonal relationships among Chinese college students. Subsequently, corresponding suitable educational suggestions are given for college students.

\section{GENDER ROLE}

Gender role refers to an idiosyncratic cluster of personal characteristics that can be linked to gender [9]. It is a system of behaviors for men and women determined by a certain culture, which includes attitudes and emotions that are considered fundamental to the composition of men and women [10].

At first, Terman and Miles divided gender roles into two modes: masculinity and femininity. Masculinity and femininity are polar opposites with single latitude, where those with a high level of femininity must have a low level of masculinity, and vice versa [11]. An individual can only belong to one of the two poles, and can never be high or low at the same time [12].

Later, Bem compiled the Bem Gender Role Questionnaire (CSRI), which divided gender roles into four types: masculine, feminine, androgynous and undifferentiated [3]. So far, studies on gender roles have mostly agreed with the four BEM classification models, in which masculinity and femininity are regarded as unisexual, androgyny and undifferentiated are regarded as non-unisexual [12]. According to the relationship between gender roles and mental health or adaptability, there are three theoretical models: the congruency model, the androgyny model and the masculine model, showing different indications about the ideal type of gender role [13]. Recently, in the contemporary west, the traditional congruence model has no market. Although the androgynous model was originally proposed as an ideal gender role model, a large number of empirical studies and a series of meta-analyses based on these studies have shown that the masculine model is the most ideal model.

\section{CHINESE COLLEGE STUDENTS' INTERPERSONAL RELATIONS}

College students are a group that attracts much attention from the society. They refer to a group of people who receive basic higher education and professional higher education yet not graduate. They are experiencing an important stage of adulthood when social skills are valued. As their life and study are mainly carried out on campus, communication and interaction with people are hardly avoided. Interpersonal relationship refers to the emotional connection between people formed through direct communication [14]. It is the most direct psychological relationship between people in the process of different behaviours [15]. In school, college students build interpersonal relationships with teachers, peers, roommates, co-worker and romantic partner. It is common for them to encounter a variety of disturbing factors in campus life. Individuals with good interpersonal skills can communicate with others more effectively and get satisfaction from others and the society. On the contrary, without social communication skills, it will be difficult to maintain interpersonal relationships and feel lonely [16]. The research on interpersonal relationship of college students includes many aspects, e.g., cultural, social, family and endogenous psychological factors. Among them, endogenous psychological factors contain the gender role types of college students.

\section{INFLUENCE OF GENDER ROLE ON INTERPERSONAL RELATIONS}

\subsection{Masculinity}

Individuals with masculine characteristics are less troubled in interpersonal communication and have a certain advantage in communication [1]. This can be explained through the quality of masculine gender role type and the growing society that caters for masculine features in interpersonal relationship.

The masculine gender role type stereotypically associated with traits such as being assertive, independent, ambitious, active and bold [17]. With those traits, one will actively respond to pressure in interpersonal relationships, and feel confident and satisfied [1]. In other words, people will actively negotiate with their peers and express their thoughts and feelings confidently. Hence, such personal traits can enhance the establishment and maintenance of interpersonal relationships.

The development of social change desires for the characteristics of assertiveness, dominance, and leadership in workplace, which results masculinity in preferable position in social contact [18]. Previous research reports that both men and women increasingly endorsed the masculine-stereotyped personality traits [1] 
The unique benefits of masculine gender role type can be reflected through women with masculine traits. In Twenge's meta-analysis [18], a sharp increase in women's BSRI-measured masculinity corresponds to their entry into the workforce. As more women anticipate entering the workforce, they would develop traits that make it necessary for them to succeed in that realm. With the preference of those non-traditional traits for women, they are more easily to be hired and accepted by her peers with those characteristics. As a consequence, they can quickly build up the interpersonal relationship with others.

\subsection{Femininity}

Nowadays, college students with feminine characteristics are partly troubled in interpersonal relationship due to various reasons, which are discussed as follows. Primarily, the self-acceptance of women is lower than that of men. Li 's research shows that masculine individuals are significantly less troubled in interpersonal relationships than feminine individuals in aspects of communication, making friends, and heterosexual contacts [19]. These findings prove that college students with feminine characteristics are more troubled than college students with masculine characteristics in interpersonal communication. Second, Compared with the college students with masculine (e.g., decisive, stouthearted, and tolerant), college students with feminine characteristics tend to be more delicated and sensitive. According to Ref [20], the degree of interpersonal relationship trouble of college students has a significant negative correlation with the existence of masculinity and androgyny, and has a significant positive correlation with feminization and undifferentiation. Additionally, for the femininity in interpersonal relationship, college students with masculine characteristics are higher than that those among college students with female characteristics. In detail, Wang suggests that regardless of individual gender, groups with significant masculine characteristics have higher psychological levels and interpersonal skills [8]. Besides, the research points out that both men or women's groups with androgynous characteristics have higher levels of mental health [8]. In consequence, the capacity of interpersonal of college students with feminine characteristics will be lower than that of groups with masculine and androgyny characteristics also has its advantages. Even so, people with femininity coul be good observers, recognizing the subtle facial and language expressions. In this case, feminine roles will be more exquisite than masculine.

\subsection{Androgyny}

The results of most researchers indicate that people with androgyny have the best interpersonal relationship. The most common view is that androgynous people have sufficient motivation and healthy attitude to interact with each other with a good personality.

According to the survey, Liu thought that people with androgynous personality can get along well with others. The reason is that people with androgynous personality have strong attraction to others, a healthy mentality to carry out interpersonal interaction, and the ability to conduct interpersonal communication. Psychology Today in the United States has conducted a large-scale investigation, found that the following personality traits are important conditions for interpersonal attraction: trustworthiness, honesty, warm-hearted, love to help others, and sincerity [6]. These traits have a lot in common with the personality traits of androgynous people. Moreover, the androgynous personality has positive perception and cognition.

In the process of interpersonal interaction, androgynous college students not only have the masculine style of self-regulation and self-control, but also have the feminine style of seeking active emotional expression and communication [21]. Moreover, they are confident that they can communicate freely with each other with any degree of intimacy they choose and make proper self-disclosure. Such information is also easy to be accepted by others, which promotes the development of interpersonal relationship more easily. Androgynous college students will also be more friendly and compassionate, more sensitive to other people's needs, understand other people's feelings. Due to a strong understanding and judgment, it' $s$ hard to misinterpret other people's behavior and it' s not easy to damage interpersonal relationships. Even in the face of interpersonal conflict, androgynous college students also have positive cognition, they can face the conflicts positively and resolve conflicts actively.

\subsection{Undifferentiation}

The survey results of most researchers denote that people who are undifferentiated have the worst interpersonal communication [8]. Based on the results, undifferentiated students generally have interpersonal barriers [21]. These people usually have no clear identification of their gender roles, nor clear life goals and lack of confidence. They have difficulties in adapting to life, which are usually depressive and pessimistic, lack of sense of responsibility, i.e., poses a great threat to normal interpersonal communication.

$\mathrm{Li}$ thinks that there are many reasons for undifferentiation [1]. For one thing, students study theoretical knowledge for a long time in school, they are more divorced from the society, i.e., the process of socialization is delayed or even stagnated. Besides, the excessive protection and overindulgence of elders for children hinder the development of positive traits (e.g., independence and bravery). For another, under the 
impact of multiculturalism, college students want to highlight personality or neutrality, which also promotes the increase of undifferentiated types of college students to a certain extent. Furthermore, if parents in the family often punish the children and adopt non democratic parenting style, it is likely to aggravate the formation of individual undifferentiation [4], especially coupling with the bad family atmosphere and the negative selfregulation of the individual.

\section{CONCLUSION}

In summary, we demonstrate that androgyny is the more favourable gender role to establish harmonious interpersonal relationship, followed by masculinity, femininity, and the undifferentiated comes the least based on literature review. Nowadays, dominated preference for masculine traits and feminized role's outstanding ability in the observation and communication imply that college educators can improve the interpersonal skills of college students by cultivating both male and female positive traits due to the flexibility of androgyny. Moreover, college education also needs to be wary about undifferentiated students since students might suffer from interpersonal barrier. Teachers can help them build up a clear identification of their gender role type. These results shed lights on the educational instructions that could shape students' gender role type.

\section{REFERENCES}

[1] Li, H. Y.. Develop gender role types and reduce barriers to interpersonal communication. Journal of Henan Radio and TV University 29.02(2016):110112.

[2] Uzzell, D., \& Horne, N. (2006). The influence of biological sex, sexuality and gender role on interpersonal distance. British Journal of Social Psychology, 45(3), 579-597.

[3] Bem, S. L. The measurement of psychological androgyny. Journal of Consulting and Clinical Psychology, 1974, 42(2):155-162.

[4] Xu, Z. H., Liu, D. Z., Huang, Q., Liu, J. G., Zhang, J., Li, Y. Q.. (2010). Research on the formation of gender roles of college students-a comparison between androgyny and undifferentiated cases. Psychological Science (01), 219-222 .

[5] Wang, P. Y.. A Review of the Research on the Gender Role of College Students. Journal of Shijiazhuang Vocational and Technical College 28.01 (2016): 70-73.

[6] Liu, Y. M.. "The androgynous personality and interpersonal communication of college students." Journal of Ningbo Radio and Television University. 01 (2006): 64-66.
[7] Liu, Z. Y. "Research on the Relationship between College Students' Gender Role and Interpersonal Disturbance." Chinese Health Service Management 26.09(2009):634-635+638.

[8] Wang, L. S. Research on the Relationship between the Sex Role Types of College Students and the Harmony of Interpersonal Relationships. Journal of Xinyu University 17.04 (2012): 42-44.

[9] Spence, J. T. (1985). Gender identity and implications for concepts of masculinity and femininity. In T. B. Sondereggr (Ed.), Nebraska symposium on motivation: Psychology and gender (Vol. 32, pp. 59-96). Lincoln: University of Nebraska Press.

[10] Yang, J., Hu, H. L., Yu, L. X.. (2008). The relationship between the gender role of college students and the quality of inter-sex communication. Psychological Development and Education (02), 8690.

[11] Terman, L. M., \& Miles, C. C. (1936). McGraw-Hill publications in psychology.Sex and personality: Studies in masculinity and femininity. McGraw-Hill Book Company.

[12] Da, H. M., Wei, R. Z., Yin, Y. L., Liu, X. J.. (2019). 10 years of research on gender roles of college students in my country: review and prospects. Journal of Longdong University (01), 137-144.

[13] Cai, H. J., Huang, X. F., Song, H. R.. (2008). The relationship model between gender roles and subjective well-being: Based on the test of Chinese college students. Psychological News (04), 474486.

[14] Jin, S. H.. Social Psychology [M]. Higher Education Press, 2005.

[15] Yang, F.. Research on the Current Situation of College Students' Interpersonal Relationship and Educational Countermeasures [D]. Shenyang Aerospace University,2019.

[16] Luo, M.. The Relationship between Interpersonal Ability, Self-esteem and Family Rearing Style of College Students [D]. Hubei University,2012.

[17] Donnelly, K., \& Twenge, J. M. (2017). Masculine and feminine traits on the Bem Sex-Role Inventory, 1993 - 2012: A cross-temporal meta-analysis. Sex Roles, 76(9), 556-565.

[18] Twenge, J. M. (1997). Changes in masculine and feminine traits over time: A meta-analysis. Sex roles, 36(5-6), 305-325. 
[19] Li, W. On the Relationship between Gender Role and Interpersonal Relationship of College Students. "Intelligence 08(2017):99 per cent.

[20] Yuan, J. J., Li, L. L., Jing, X. X.. "Types of gender roles of university students, The correlation between general self-efficacy and interpersonal distress. "Chinese Journal of Health Psychology, 750-752 pages, ISTIC (2015).

[21] Zhang, H.. (2008). Research on the relationship between gender roles and interpersonal harmony of college students. Chinese Journal of Health Psychology (03), 245-247. 